\title{
Study on Importance of Backward Student Management on College Security and Stability
}

\author{
Lei HU \\ Dept. of Art \\ Chongqing Technology and Business University \\ Chongqing, 401000, China \\ e-mail: 289592324@qq.com
}

\author{
Jiang LI \\ Dept. of Petroleum Supply Engineering \\ Logistical Engineering University \\ Chongqing, 401311, China \\ e-mail: lijiang830@163.com
}

\begin{abstract}
The article author makes a backward student better through ideological and political management, which shows that although the ideological and political management of backward students in college is more difficult, the effect is significant as long as the educators carry out practical works with high sense of responsibility and proper methods, and can bring security and stability to the college.
\end{abstract}

Keywords-student management; method; importance; security and stability

\section{INTRODUCTION}

The 21 st century is the technology information age based on the knowledgement [1], in this modern society with fast technological development, each country needs a large number of coordinated, enterprising, creative people with good characters and physical and mental health that can make the country have the talent to win in the fierce competition [2].

Colleges are the bases for cultivating all kinds of professionals. As the cradle of college students who fostered the future construction missions, colleges still play an important role [3]. College students have always been regarded as the hope and future of the country. It is the reserve army of the socialist construction. It is the inheritor of human civilization and the excellent group of young people who are full of vitality and creativity. However, dues to the influence of examinations and social negative phenomena, some college students have many bad habits in life or learning, which plays negative roles in the formation of characters and the correct concept of life [4].

\section{BACKGROUND}

Student A, Male, he was appointed as the temporary student cadre office at the beginning because of the excellent academic performances. But in the life and learning progress, his shortcomings such as extreme personality, narrow-minded, poor psychological capacity are gradually revealed. For example, the test results of several courses in the early enrollment are not satisfactory which affected his study mood during the whole freshman semester. Compared with the heavy study work in high school, life in college is relatively free, he did not put time and energy on learning and instead he began to play online games overnight with absenteeism. At first this situation happens occasionally, and then the internet cafes almost become the main battle of his life. For this reason, he failed in two final exams in the freshman semester, when the time came to the second semester he no longer serves as the student cadres of their class which makes him more self-abandonment. Because of the huge gap between the college and high school situation, he almost give up himself, he stayed in internet cafes all day to play online games with continuous absenteeism and did not want to communicate with anyone, he was reluctant to say a few words even with the bedroom classmates. His classmates and the counselor noticed his changes. First, the article author let the class committee to do his ideological work, but the effect is not obvious. So the article author got the students and made the situation clear. His poor psychological ability to bear frustration made his wish to learn weak after he failed in two exams, at the same time, some of the disharmony elements also made him discord with the surrounding students, even with the bedroom classmates. He admitted that he felt very decadent, and thought to give up.

\section{ManAgement PROCESS}

The author gives up the rest time to talk with the student in order to open his mind. A told the author that because of the study frustration, he has no interests in the college life and learning, so addicted to online games to escape from it. Get rid of these, the author told him that occasional frustration is normal in the life, the key is not to give up, can't easily give up himself in particular. College is the excessive stage to the community of society, college student should learn to accept life. The occasional frustration can't represent anything. Through the communication he gets the proper learning attitude. The author arranged two responsible students to help him specially, from the classroom notes to home works, explain the learning questions patiently, and ask the relevant substitute teacher to give their help, such as asking him more questions in the classroom, the correction of his work is relatively strict and so on to create a good learning environment through these ways and achieves good results. In life, the author concerned the student with every little things, such as asking his learning and living conditions and so on. The student starts to regain self-confidence in learning, no longer addicted to online games and has a great improvement after two months. He finds an ideal work unit in the junior period. 


\section{THINKING}

This case makes the author deeply understand that in order to do a good job in the college student management, the most important way is to make deep contact with students. The only way to do the student management work well is to analyze the case of each student carefully, it will be able to exchange for students' identity with their own love and patience [5].

This case also makes the author deeply appreciate that new methods of the college student management are urgent to be found in the new socialism. At present, our country's social economy develops rapidly, the socialist market economic system is gradual established and perfected which promotes the reform and development of higher education. At the same time, it also puts forward higher requirement to the student management work.

Under the new situation, the environment, connotation and object of student management work have also undergone some new changes, the original management methods and means of work have emerged a certain degree of adaptation. At present, the changes in student management work mainly show the following two characteristics. From the management work environment, as a result of the social environment change, the external managing environment is more complex. Market economy greatly liberates the productive forces, but it also brings some negative impacts to people's life and cognitive areas. From the object of management work, compared with the previous, contemporary college student's thinking are more active, their personality is more publicity, the way they get information is more complex. On the other side, their world view, outlook on life, values are still in the formation period which is not mature, so they can easily be affected by bad thoughts and information [6-7]. In order to respond to these changes, the author believes that the management work of college counselors should be based on in-depth and meticulous understanding of the real situation of the student with lots of early work, takes honesty and appropriate motivation as the important starting point of college student management, and promotes student management work solidly.

(1) Make in-depth and meticulous understanding of the real situation of the students [8]. For a long time, college counselors have always attached great importance to the development of various aspects of college students, but sometimes, the way of education is not appropriate, or the degree of patience is not enough, or stay in the holding of the class meeting too much, so much facts prove that the effect is not good, students who need help alone do not get tangible help or achieve improvement. Therefore, the author believes that counselor should focus more on the practical aspects during the college student management.

(2) The implementation of counseling links should focus more on one to one help [9]. For example, if the counselor finds out that a student has difficulties in life or learning, the counselor should take the initiative to find the students and help him in good faith, at the same time mobilize the student leaders to provide more timely help in life and learning.
Take the means of equal communication with the student, to help students solve practical problems one to one. It will help to win the trust of students and also helps to solve the problem.

(3) Analyze cases carefully, sum up the experience of solving the problems [10]. Many single cases may be parts of the student's questions. As a counselor, it is necessary to analyze the student cases in the college student management seriously, analyzes the reason of the problem, makes in-depth and patiently understanding of the student's real situation by lots of preliminary works, takes preventive measures, try to avoid the recurrence of similar student cases. At the same time, careful analysis of the problems and experience of solving the problems are needed so as to achieve better results in future college students management.

(4) Give more encouragement and less criticism, build forward platform for the backward students [11-12]. Everyone has their own advantages, analyzes the strengths of backward students carefully, provide opportunities to show their expertise, let them find self-confidence in the work and learning, and brings this self-confidence to their lives and serves multiple purposes.

\section{CONClusions}

Through the analysis above, it is easy to see the effect of student management work is closely related to the degree of the basic work. It only works with in-depth and meticulous understanding of the real situation of students with driving the other students to act together so as to create a good working environment and to create a safe and stable college environment.

\section{REFERENCES}

[1] Yan-hua WU. Dormitory Interpersonal Relationship - A Breakthrough Point of Ideological and Political Work in Colleges and Universities[J]. Journal of Suzhou Education College, 2007,(5):33-35.

[2] Li Wei-yuan, Cui Shi-ying. Take the scientific development concept as a guide to build " the new harmonious dormitory culture of the after 90" [J]. China Science and Technology Innovation Guide, 2009, (7): 99.

[3] Liu Jun, Cheng Yi. Resolving the Contradiction of College Dormitory and the Reconstruction of Interpersonal Relationship-- Based on practical work case perspective[J]. Educational Theory Research, 2009, (2): 151-152.

[4] Jiang Ming-jun. On the theoretical significance and practical significance of the cultivation of civilization [J] .Journal of Ideological and Political Education, 2007,01: 113-114.

[5] Zhang Guo-qi. The characteristics of modern civilization self-cultivation[J]. Ideological and Education, 2008,21: 48-52.

[6] Li Dong-ping. College students "civilized self-cultivation" education [J]. Journal of Xiangtan Normal University (Social Science Edition), 2001,02: 132-134.

[7] Zhang Guo-qi, Wang Zhong-qiao. The perspective of building a socialist harmonious society, the value of modern civilization and self-cultivation [J]. Journal of Ideological and Education, 2005,09: 53-56.

[8] Liu Ge, Niu Wei. The student civilization and self-cultivation education [J]. Science and Technology Guide , 2010,07: 133 - 135.

[9] Lin Wei,Xia Ying-chun. Student management work art of college counselors [J]. Guangxi Education, 2009,04: 36. 
[10] Zhang Shui-sheng. An example of the emphasis on education [J]. Journal of Qiqihar University (Philosophy and Social Sciences), 2002, (11): $135-136$
[11] Wei Yan. College counselor style construction [J]. Talent Development, 2010, (02): 51-53.

[12] Yang Jin-bao. The new work model of College counselors [J]. Heilongjiang Science and Technology Information, 2010, (08): 150. 